\title{
Navigated macular laser decreases retreatment rate for diabetic macular edema: a comparison with conventional macular laser
}

This article was published in the following Dove Press journal:

Clinical Ophthalmology

15 January 2013

Number of times this article has been viewed

\author{
Aljoscha S Neubauer ${ }^{1, *}$ \\ Julian Langer ${ }^{1, *}$ \\ Raffael Liegl' \\ Christos Haritoglou' \\ Armin Wolf' \\ Igor Kozak ${ }^{2}$ \\ Florian Seidensticker \\ Michael Ulbig' \\ William R Freeman ${ }^{2}$ \\ Anselm Kampik' \\ Marcus Kernt' \\ 'Ludwig-Maximilians University, \\ Department of Ophthalmology, \\ Munich, Germany; ${ }^{2}$ Jacobs Retina \\ Center, University of California San \\ Diego, La Jolla, CA, USA \\ *These authors contributed equally \\ to this work
}

Correspondence: Marcus Kernt Department of Ophthalmology, Ludwig-Maximilians-University

Munich, Mathildenstrasse 8, 80336

Munchen, Germany

$\mathrm{Tel}+49895160381 \mathrm{I}$

$\mathrm{Fax}+498951605160$

Email marcus.kernt@med.uni-muenchen. de
Background: The purpose of this study was to evaluate and compare clinical outcomes and retreatment rates using navigated macular laser versus conventional laser for the treatment of diabetic macular edema (DME).

Methods: In this prospective, interventional pilot study, 46 eyes from 46 consecutive patients with DME were allocated to receive macular laser photocoagulation using navigated laser. Best corrected visual acuity and retreatment rate were evaluated for up to 12 months after treatment. The control group was drawn based on chart review of 119 patients treated by conventional laser at the same institutions during the same time period. Propensity score matching was performed with Stata, based on the nearest-neighbor method.

Results: Propensity score matching for age, gender, baseline visual acuity, and number of laser spots yielded 28 matched patients for the control group. Visual acuity after navigated macular laser improved from a mean $0.48 \pm 0.37 \log$ MAR by a mean +2.9 letters after 3 months, while the control group showed a mean -4.0 letters $(P=0.03)$. After 6 months, navigated laser maintained a mean visual gain of +3.3 letters, and the conventional laser group showed a slower mean increase to +1.9 letters versus baseline. Using Kaplan-Meier analysis, the laser retreatment rate showed separation of the survival curves after 2 months, with fewer retreatments in the navigated group than in the conventional laser group during the first 8 months $(18 \%$ versus $31 \%$, respectively, $P=0.02$ ).

Conclusion: The short-term results of this pilot study suggest that navigated macular photocoagulation is an effective technique and could be considered as a valid alternative to conventional slit-lamp laser for DME when focal laser photocoagulation is indicated. The observed lower retreatment rates with navigated retinal laser therapy in the first 8 months suggest a more durable treatment effect.

Keywords: navigated focal laser, macular laser, Navilas ${ }^{\circledR}$, diabetic macular edema, diabetes mellitus, diabetic retinopathy

\section{Introduction}

Diabetic macular edema (DME) is the leading cause of vision impairment in patients with diabetes mellitus. ${ }^{1-5}$ It is estimated that $29 \%$ of diabetic patients with more than 20 years of diagnosed diabetes mellitus will develop DME. ${ }^{2,4}$ It mostly affects the working age population, imposing a significant burden both on society and on individual patients, a burden that is expected to increase with the rising prevalence of diabetes. ${ }^{6,7}$

With the introduction of various pharmacological therapies, such as steroids and antiangiogenic agents, the treatment of DME has been expanded, and is not limited to standard laser photocoagulation anymore. However, although improvements 
in best-corrected visual acuity have been observed with steroids and anti-vascular endothelial growth factor (VEGF) agents, robust long-term clinical trial evidence is currently limited. ${ }^{8-11}$ Recently, the Early Treatment Diabetic Retinopathy Study (ETDRS) protocol was demonstrated to be better at stabilizing vision and had a longer sustained benefit than intravitreal triamcinolone, ${ }^{12}$ and while anti-VEGF therapy has been proven to be an effective therapy to restore vision at 3 years, studies to date support a continued role for laser photocoagulation in primary and salvage scenarios. ${ }^{13}$ Most recently, ranibizumab, an anti-VEGF agent, received approval from the US Food and Drug Administration for DME. Currently, treatment recommendations for DME are based on involvement of the center of the macula. Laser photocoagulation remains the standard of care for DME without center involvement or for DME with center involvement without vision loss, and current ETDRS guidelines remain appropriate for this subpopulation of DME. ${ }^{14}$ It also remains a good treatment option given that it is the most cost-effective longterm treatment for DME. ${ }^{15,16}$

Furthermore, the original ETDRS protocol using argon laser photocoagulation with a visible end point has been modified over the years as new technology has evolved. ${ }^{17-20}$ Technical advances, including subthreshold techniques, ${ }^{21}$ and pattern laser generation ${ }^{22}$ have transformed laser photocoagulation into a less painful and more efficient mode in the treatment of retinal diseases. More recently, the development of navigated laser photocoagulation that combines fluorescein angiography with image stabilization and tracking has facilitated more efficient, accurate, and precise focal photocoagulation, allowing delineation of the spots/areas most appropriate for treatment. ${ }^{23-25}$ The ability to preplan and deliver the planned spots in an automatic mode is an additional advantage over conventional slit-lamp manual lasers. It makes necessary the completion of the planned spots led by the system and not by the memory of the surgeon. This translates finally into a more standardized and complete laser treatment. In addition to documentation, safety, and patient comfort, the main theoretical advantage lies in retinal navigation, which may help to improve clinical outcomes with laser application.

However, to date, there are limited data regarding the clinical efficacy and benefits of using navigated retinal laser therapy over traditional slit-lamp laser. Randomized controlled trial data comparing navigated laser therapy versus conventional slit-lamp microscope-based laser treatment, are lacking. We performed a propensity score matched-pairs study based on prospective patient data from two specialist centers using navigated retinal therapy. The aim was to investigate the necessity of retreatment and visual acuity outcome of navigated retinal laser therapy for DME.

\section{Materials and methods Navigated laser therapy}

The scanning slit laser photocoagulator, Navilas ${ }^{\circledR}$ (OD-OS $\mathrm{GmbH}$, Teltow, Germany) was CE-marked and approved by the US Food and Drug Administration in 2009, and its principal operation has been described elsewhere. ${ }^{23}$ In brief, the Navilas combines imaging, laser application planning, and treatment in one computer-based device. It fundamentally differs from most other laser devices by not being added to a slit-lamp, but being a scanning slit-based instrument, capturing approximately 25 images per second in imaging or treatment mode. For focal laser treatment, the field of view is 50 degrees, which is displayed on a monitor. Optical resolution with the instrument used in this study was $1280 \times 1024$ pixels for that angle, resulting in approximately 20-26 pixels per degree. Because of the slit imaging principle, color images of high contrast and sharpness are obtained. ${ }^{23}$ Another difference from the slit-lamp-based laser devices is the touch screen monitor used for imaging, planning, and treating fundus changes. This allows the retina specialist to plan laser spots on the screen for focal treatments, and then apply either semiautomated patterns or single spots. A prepositioning mode may be used to advance the targeted aiming beam from the target position automatically to the next position, and the preplanned target can be stabilized on the fundus. For treatment, the surgeon performs the laser treatment manually after verifying the target lock.

\section{Patients treated with laser photocoagulation}

Consecutive patients were recruited in 2009 and 2010 from the outpatient clinic of the Department of Ophthalmology, Ludwig-Maximilians-University, Munich, and from Jacobs Retina Center, University of California, San Diego. Patients with diabetes mellitus (based on World Health Organization criteria) who were eligible for focal laser treatment as defined by ETDRS criteria were included in this study. Written informed consent was obtained from all patients. The study conformed to the principles expressed in the Declaration of Helsinki, and institutional review board approval was obtained at each participating center. Eyes were excluded if there were pre-existing retinal conditions that preclude visual improvement despite resolution of macular edema, such as age-related macular degeneration. All patients had follow-up 
at least every 3 months. Retreatment was performed with the same device if retinal thickening did not improve $(\geq 100 \mu \mathrm{m}$ on optical coherence tomography [OCT]) or visual acuity did not improve by at least five letters.

\section{Imaging}

Navilas imaging was performed with a fully dilated pupil after clinical examination and before laser therapy, and consisted of several color images. Fluorescein angiography was performed as needed for treatment planning, ie, before treatment and during follow-up either on the navigated laser device or on a separate imaging system (HRA, Heidelberg Engineering, Heidelberg, Germany). Spectral-domain OCT (Spectralis, Heidelberg Engineering, Heidelberg, Germany) was performed as needed for individual patient management.

\section{Laser planning and treatment}

Laser planning and treatment was performed adhering to ETDRS principles. Microaneurysms were targeted if identified as source of leakage on fluorescein angiography. With the Navilas, the obtained color image was used for planning laser spots. The retina specialist manually planned laser spots by applying automated patterns and single spots as appropriate on the color image, thus generating a detailed treatment plan. For navigated laser application, semiautomatic pattern laser application was conducted based on the treatment plan. A spot size of $100 \mu \mathrm{m}$ was always selected, with a time per spot of $100 \mathrm{msec}$. Power settings of the green (532 nm) frequency doubled Nd:YAG laser were adjusted manually from a standard $100 \mathrm{~mW}$ such that spots showed a moderate whitening. The prepositioning mode was used to advance the targeting aiming beam automatically from each targeted retinal position to the next position after the aiming beam and preplanned target were stabilized on the living fundus. The retina surgeon actuated the laser manually after verifying the target lock. An alternating infrared to color video fundus visualization mode was applied to allow post treatment observation of the retinal burn for 2-3 seconds after each application without patient discomfort.

\section{Conventional laser therapy}

Conventional laser therapy was performed during the same time period. Planning was performed on paper, adhering to the same principles (modified ETDRS scheme, targeting microaneurysms only in case of leakage). All treatment plans were performed by an experienced attending physician at the respective institution. Laser therapy was performed using a slit-lamp-based green laser (532 nm wavelength, Visulas 532s, Carl Zeiss Meditec AG, Jena, Germany; laser settings: $100 \mathrm{~mW}$ power, $100 \mathrm{msec}$ pulse duration, $100 \mu \mathrm{m}$ spot size), A suitable contact glass, either Volk Area Centralis ${ }^{\circledR}$ or Mainster $^{\circledR}$, was used. Documentation was performed by paper drawing and recording laser parameters. Figure 1 shows a sample of planning and post treatment images for conventional and Navilas laser treatment.

\section{Propensity score matching and data analysis}

All data were collected in a MS-Excel 2000 spreadsheet (Microsoft Corporation, Redmond, WA) and analyzed using the Statistical Package for Social Sciences version 19.0 for Windows ${ }^{\circledR}$ (SPSS Inc, Chicago, IL). Patients were either treated with navigated retinal laser (Navilas) or conventional, slit-lamp-based laser during the same time period. To minimize bias when comparing the two groups, we matched the patient group treated with Navilas with the patient group receiving conventional laser treatment for DME. Propensity score matching was applied for this. Propensity score matching is a method of balancing observed characteristics that reduces selection bias and strengthens causal inferences in observational studies, ${ }^{26,27}$ and is a method of multivariate matching that also
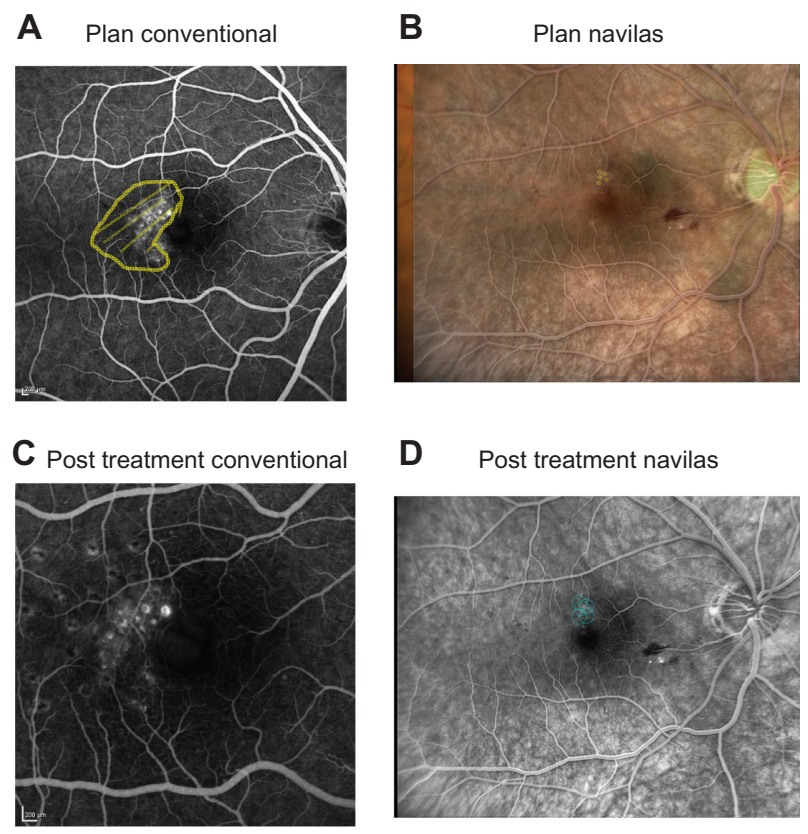

Figure I Examples before and after laser. Two sample patients conventionally treated (patient A) or treated by $\mathrm{Navilas}^{\circledR}$ (patient B). (A) Fluorescein angiography with treatment area marked. (B) Navilas fundus photograph with fluorescein angiography overlay and preplanned laser spots. (C) Three-month follow-up on fluorescein angiography. (D) Fluorescein angiogram with executed laser treatment spots marked by Navilas. 
allows for close but not exact matches. ${ }^{28}$ This allows for simultaneous matching with respect to a large number of covariates in relatively small data sets, unlike exact matching, for which the minimal sample size required increases exponentially with each additional covariate matched. Propensity scores were estimated from a logistic regression model that included all control variables. In this case, the propensity score was the predicted probability, on the basis of observed variables, of a given patient being treated with navigated retinal laser for DME. The resulting propensity scores were then entered into the Stata PSMATCH2 command for 3:1 matching. Matching was limited to the area of common support of the propensity score, ie, the area in which the distribution of propensity scores for patient being treated with navigated retinal laser for DME overlaps with the distribution of propensity scores for patient having had conventional laser for DME.

This excluded patients in the conventional laser group who, on the basis of observed characteristics, were the least like those in the opposing group and thus were least likely to produce a close match. Matches were made within a defined distance of 0.1 standard deviation of the propensity score. The resulting matched sample was used for analysis of all outcomes. Because small differences between groups remain after propensity score matching, the estimated propensity scores and all covariates were included in all analyses of the matched samples. ${ }^{29}$ All analyses were conducted with Stata MP 11.0 (Stata, College Station, TX).

\section{Results}

\section{Baseline data for unmatched and matched groups}

A total of 46 eyes were treated by navigated laser therapy and 119 by conventional laser. Before matching, the number of laser spots performed per patient with navigated therapy was $105 \pm 94$, which was significantly higher than with conventional laser $(43 \pm 36 ; P<0.001)$. Follow-up time was significantly shorter for Navilas patients than for conventional patients (median 6.8 versus 13.5 months, $P<0.001)$. Propensity score matching for age, gender, baseline visual acuity, number of laser spots, and follow-up time yielded 28 matched patients for the control group. Visual acuity at baseline was $0.48 \pm 0.37 \log$ MAR for Navilas and $0.43 \pm 0.36 \log$ MAR (not statistically significant) for conventional laser before matching. Table 1 lists the baseline characteristics for the matched patient groups, which were very similar between the two groups.

\section{Clinical outcomes}

\section{Change in BCVA}

BCVA remained stable (no loss $>3$ lines/15 letters) in all patients included in the matched comparison after 3 and 6 months. Mean increase from baseline $0.48 \pm 0.37 \log$ MAR was 3.3 letters for the navigated laser therapy group after 6 months, while the conventional laser group increased from baseline $0.49 \pm 0.40 \log$ Mar by mean 1.9 letters. Visual outcomes at the 3-month time point were better for the Navilas group (mean increase 2.9 letters) versus conventional laser group, which lost a mean -4.0 letters $(P=0.03)$. However, the difference did not reach statistical significance after matching data for age, gender, baseline visual acuity, and number of laser spots after 6 months $(P=0.08)$. Figure 2 shows the course of visual acuity, illustrating the significantly faster gain in visual acuity in the Navilas group. In addition, after matching for age, gender, baseline visual acuity but unmatched for the number of laser spots, the difference between groups increased numerically. At the 3-month time point, visual acuity was significantly better for the Navilas group $(P=0.03)$ than for the conventional laser group (mean increase 2.9 letters [Navilas] versus mean decrease -6.3 letters [conventional laser], see Figure 3).

\section{Retreatment rate}

The laser retreatment rate using Kaplan-Meier analysis showed separation of the survival curves after 2 months, with fewer retreatments in the navigated group during the first 8 months $(P=0.02)$. Figure 4 shows the retreatments over time. The cumulative retreatment rate in the eyes that received navigated laser was $18 \%$ and $31 \%$ in the eyes

Table I Baseline patient characteristics

\begin{tabular}{llll}
\hline Variable & $\begin{array}{l}\text { Navilas group } \\
(\mathbf{n}=\mathbf{4 6})\end{array}$ & $\begin{array}{l}\text { Conventional laser control group } \\
\text { (after matching), } \mathbf{n = 2 8}\end{array}$ & $\begin{array}{l}\text { Statistical } \\
\text { significance }\end{array}$ \\
\hline Age (years) & $61 \pm 11.02$ & $61 \pm 11.7$ & $P=0.94$ \\
Gender (\% female) & $24 \%$ & $18 \%$ & $P=0.48$ \\
Baseline visual acuity & $0.48 \pm 0.37$ & $0.49 \pm 0.40$ & $P=0.90$ \\
Laser spots planned $(\mathrm{n})$ & $105 \pm 94$ & $74 \pm 48$ & $P=0.20$ \\
\hline
\end{tabular}




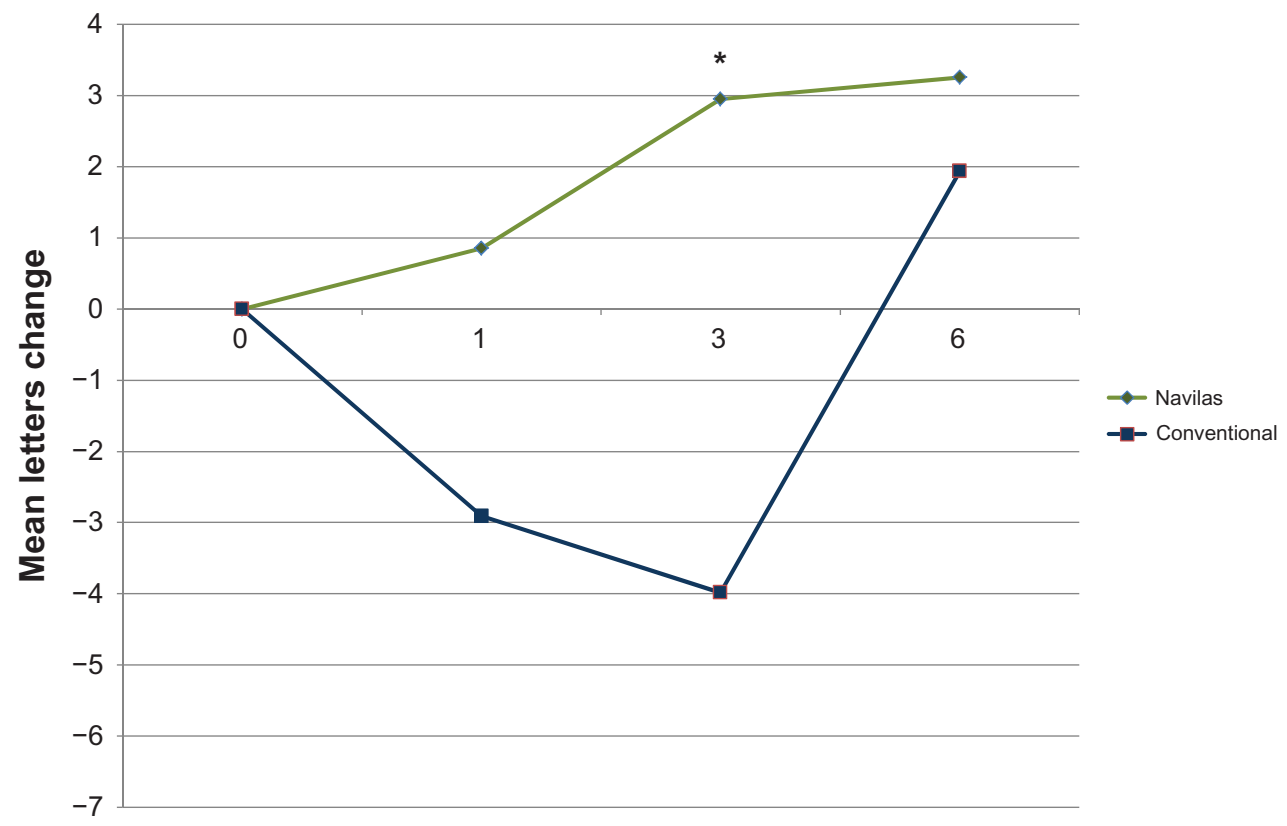

Months follow-up

Figure 2 Visual acuity change over time (mean letters gained).

Note: *Indicates statistical significance.

that received conventional slit lamp laser at 8 months after treatment.

\section{Discussion}

Over the past three decades, the standard treatment for DME has been macular laser photocoagulation. In the ETDRS, laser therapy reduced the relative risk of losing 15 letters of visual acuity by $50 \%$ compared with untreated eyes. ${ }^{30,31}$ Visual improvement ranging from 0.9 letters ${ }^{9}$ to three letters ${ }^{32}$ for patients receiving macular laser has been reported recently according to ETDRS guidelines. At 2 years, $21 \%$ eyes exhibited more than three lines of improvement, suggesting a delayed effect. ${ }^{8}$

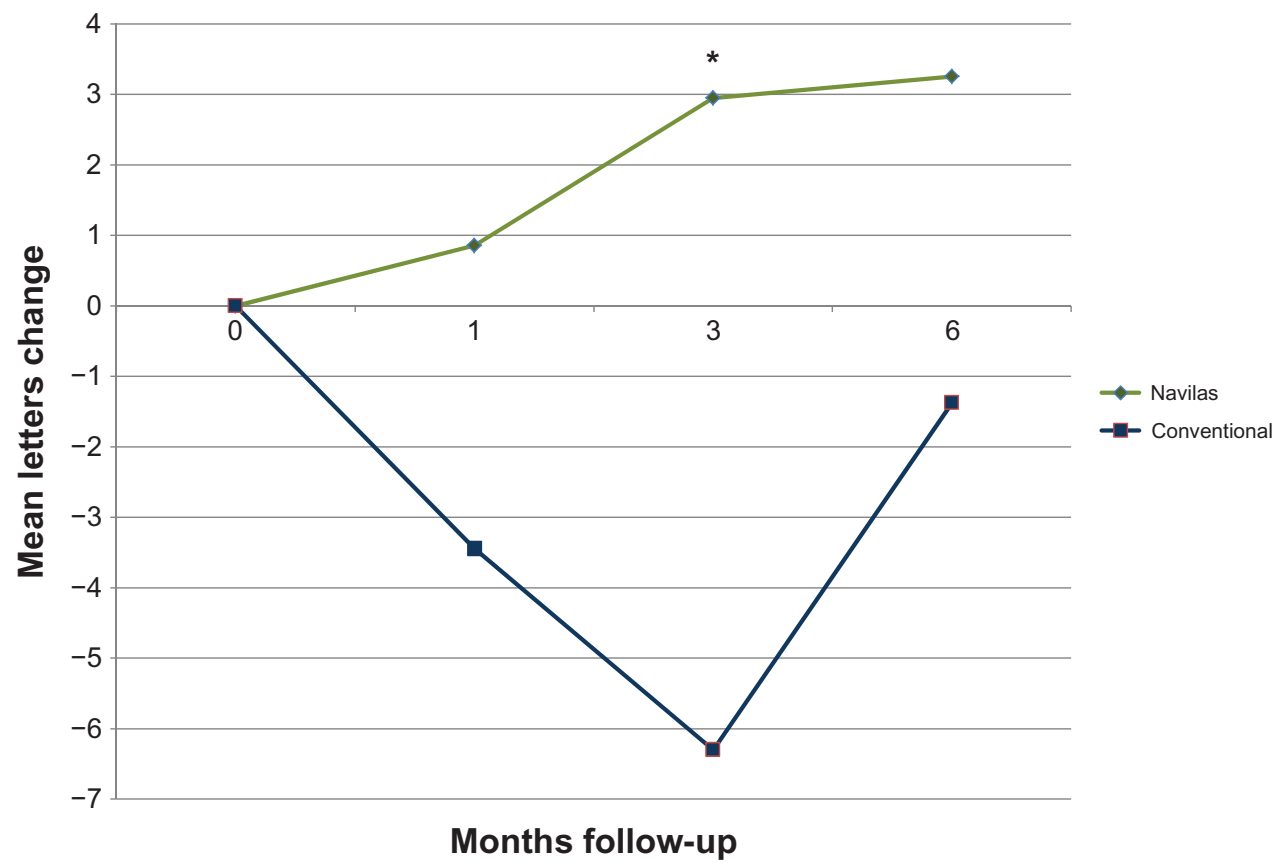

Figure 3 Visual acuity change over time [letters gained] matched for age, gender, and baseline visual acuity but unmatched for the number of laser spots. Note: *Indicates significant difference. 


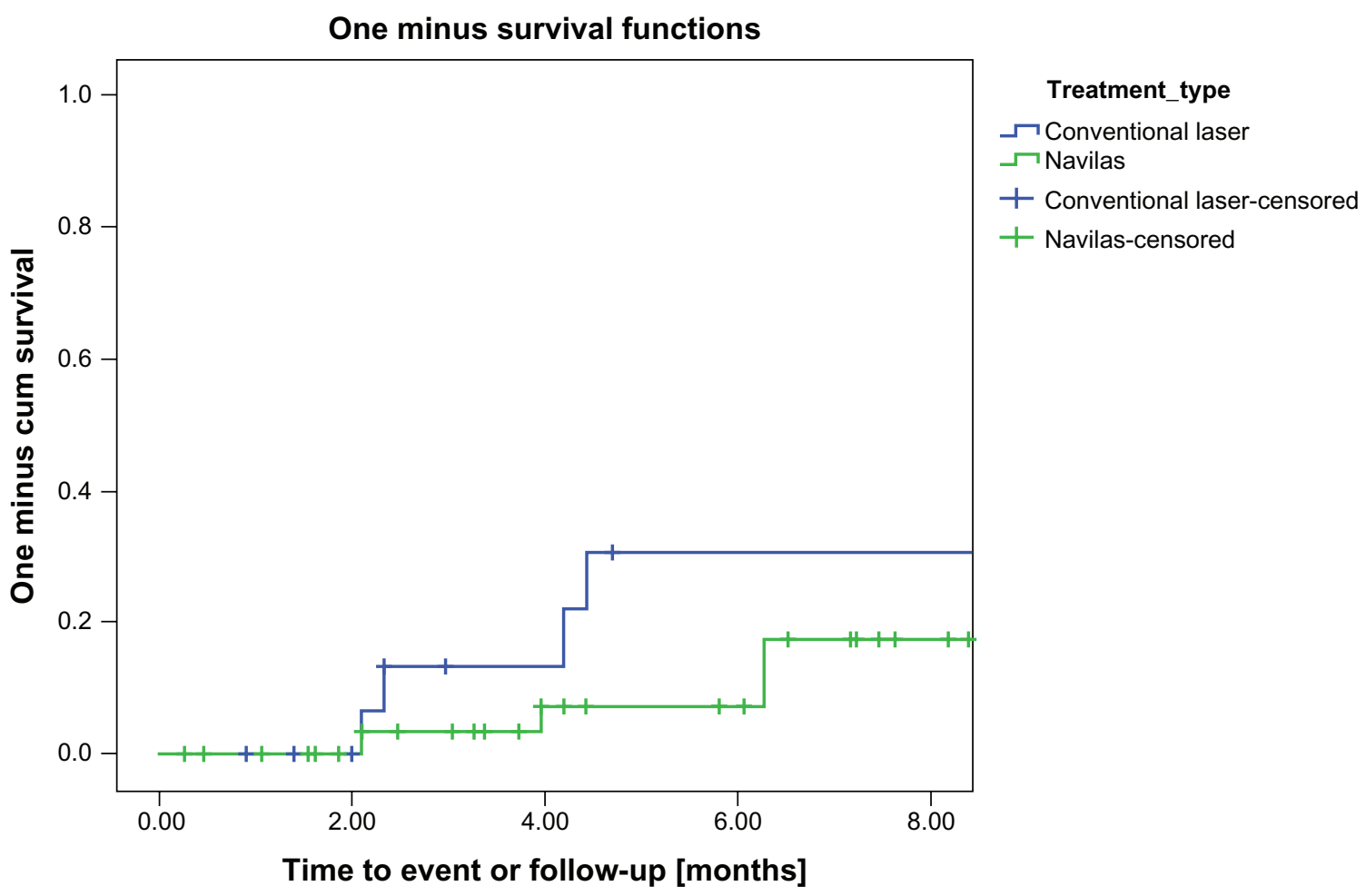

Figure 4 Kaplan-Meier analysis of retreatment rate.

Notes: After approximately 2 months, the survival curves separate, indicating more retreatments for the conventional laser group $(P=0.02)$. The 3 -month period after first laser treatment, in which usually no retreatment is performed, is marked green.

Slit-lamp manual laser photocoagulation has been the conventional way of delivering focal/grid treatment for DME. With the introduction of navigated laser photocoagulation, this traditional concept has changed to a computer-based treatment with an eye-tracking system. This method of laser delivery has been shown to have several advantages over standard manual laser. First, it is more accurate compared with manual laser, ${ }^{25}$ and accuracy becomes crucial when treating close to the fovea and targeting individual microaneurysms. Reports by the Diabetic Retinopathy Clinical Research (DRCR) network have demonstrated that focal microaneurysm treatment with light grid was superior to modified grid therapy alone in DME as judged by vision improvement and retinal thickness reduction..$^{33}$ Second, it allows standardization of macular laser treatments. The present study reports for the first time that higher accuracy resulted in less retreatment over the first 6-8 months when compared with slit-lamp laser treatments. Visual acuity improved consistently, indicating effective laser treatment. Even if the beneficial effect of laser is slow and delayed per se, we believe that 6-8-month follow-up was enough to assess the differential clinical effect of navigated laser treatment versus conventional laser application in this pilot study.
The course of visual acuity confirms that the differences between the two methods were largest after 1-3 months, showing a statistically significant difference 3 months after laser treatment.

Interestingly, we observed that before statistically matching the study groups, the total number of laser spots was significantly higher when using navigated laser than conventional laser. While this effect was mostly eliminated after propensity score matching (differences not statistically significant) our explanation is that, in the navigated group, the physician can directly observe execution of the treatment plan that is projected real-time and can see how many laser spots remain to be applied. That is why (s)he is obliged to complete the treatment.

Recently, the therapeutic options for center-involved DME have been shifted to intravitreal anti-VEGF therapy. Initial anti-VEGF monotherapy is widely accepted and although the role of adjunctive laser is unclear, the 2-year outcomes from the READ- $2^{10}$ and DRCR.net studies ${ }^{8}$ provide the first evidence for a reduction in the number of ranibizumab injections when combined with laser. However, anti-VEGF therapy still leaves an unmet clinical need and unanswered questions that include how to improve vision in patients who do not respond to anti-VEGF and ways towards reducing the 
treatment burden in patients with DME. Our current report aimed to confirm that a more accurate laser treatment resulted in a more effective treatment measured by the number of retreatments. The second step will be to standardize this method of performing macular laser therapy and use it as part of combination therapies. Ultimately, this will likely reduce the number of intravitreal injections and reduce the patient burden.

The limitations of our current study include the relatively small patient series and the fact that patients were not randomized to treatment. However, by propensity score matching, we could minimize any potential bias. This method is becoming increasingly popular for analysis of nonrandomized data and to obtain best possible evidence.

Taken together, we have demonstrated that navigated laser therapy enables a reduced retreatment rate and faster visual acuity gain compared with conventional laser during the first 6-8 months after treatment. These data suggest a more durable treatment effect that can potentially maintain visual outcomes improved by anti-VEGF for patients with DME. It would also offer a more effective laser treatment for eyes in which laser is still the primary indication or rescue treatment for nonresponders to anti-VEGF.

\section{Disclosure}

The authors report no conflicts of interest in this work.

\section{References}

1. Klein R, Klein BE, Moss SE. The Wisconsin Epidemiological Study of Diabetic Retinopathy: a review. Diabetes Metab Rev. 1989;5:559-570.

2. Klein R, Klein BE, Moss SE, Cruickshanks KJ. The Wisconsin Epidemiologic Study of Diabetic Retinopathy. XV. The long-term incidence of macular edema. Ophthalmology. 1995;102:716.

3. Klein R, Klein BE, Moss SE, Davis MD, DeMets DL. The Wisconsin Epidemiologic Study of Diabetic Retinopathy. IV. Diabetic macular edema. Ophthalmology. 1984;91:1464-1474.

4. Klein R, Knudtson MD, Lee KE, Gangnon R, Klein BE. The Wisconsin Epidemiologic Study of Diabetic Retinopathy XXIII: the twenty-fiveyear incidence of macular edema in persons with type 1 diabetes. Ophthalmology. 2009;116:497-503.

5. Klein R, Moss SE, Klein BE, Davis MD, DeMets DL. The Wisconsin Epidemiologic Study of Diabetic Retinopathy. XI. The incidence of macular edema. Ophthalmology. 1989;96:1501-1510.

6. Chen E, Looman M, Laouri M, et al. Burden of illness of diabetic macular edema: literature review. Curr Med Res Opin. 2010;26:1587-1597.

7. Wild S, Roglic G, Green A, Sicree R, King H. Global prevalence of diabetes: estimates for the year 2000 and projections for 2030. Diabetes Care. 2004;27:1047-1053.

8. Elman MJ, Bressler NM, Qin H, et al. Expanded 2-year follow-up of ranibizumab plus prompt or deferred laser or triamcinolone plus prompt laser for diabetic macular edema. Ophthalmology. 2011;118:609-614.

9. Mitchell P, Bandello F, Schmidt-Erfurth U, et al. The RESTORE study: ranibizumab monotherapy or combined with laser versus laser monotherapy for diabetic macular edema. Ophthalmology. 2011;118: $615-625$.
10. Nguyen QD, Shah SM, Khwaja AA, et al. Two-year outcomes of the ranibizumab for edema of the macular in diabetes (READ-2) study. Ophthalmology. 2010;117:2146-2151.

11. Stewart MW. Anti-vascular endothelial growth factor drug treatment of diabetic macular edema: the evolution continues. Curr Diabetes Rev. 2012;8:237-246.

12. Beck RW, Edwards AR, Aiello LP, et al. Three-year follow-up of a randomized trial comparing focal/grid photocoagulation and intravitreal triamcinolone for diabetic macular edema. Arch Ophthalmol. 2009; 127:245-251.

13. Bandello F, Cunha-Vaz J, Chong NV, et al. New approaches for the treatment of diabetic macular oedema: recommendations by an expert panel. Eye (Lond). 2012;26:485-493.

14. Treatment techniques and clinical guidelines for photocoagulation of diabetic macular edema. Early Treatment Diabetic Retinopathy Study Report Number 2. Early Treatment Diabetic Retinopathy Study Research Group. Ophthalmology. 1987;94:761-774.

15. Sharma S, Brown GC, Brown MM, Hollands H, Shah GK. The costeffectiveness of grid laser photocoagulation for the treatment of diabetic macular edema: results of a patient-based cost-utility analysis. Curr Opin Ophthalmol. 2000;11:175-179.

16. Smiddy WE. Economic considerations of macular edema therapies. Ophthalmology. 2011;118:1827-1833.

17. Campbell CJ, Noyori KS, Rittler MC, Innis RE, Koester CJ. The application of fiber laser techniques to retinal surgery. Arch Ophthalmol. $1964 ; 72: 850-857$.

18. Meyer-Schwickerath G. Light coagulation; a method for treatment and prevention of the retinal detachment. Albrecht Von Graefes Arch Ophthalmol. 1954;156:2-34. German.

19. Neubauer AS, Ulbig MW. Laser treatment in diabetic retinopathy. Ophthalmologica. 2007;221:95-102.

20. Velez-Montoya R, Guerrero-Naranjo JL, Gonzalez-Mijares CC, et al. Pattern scan laser photocoagulation: safety and complications, experience after 1301 consecutive cases. Br J Ophthalmol. 2010;94:720-724.

21. Nakamura Y, Mitamura Y, Ogata K, Arai M, Takatsuna Y, Yamamoto S. Functional and morphological changes of macula after subthreshold micropulse diode laser photocoagulation for diabetic macular oedema. Eye (Lond). 2010;24:784-748.

22. Bolz M, Kriechbaum K, Simader C, et al. In vivo retinal morphology after grid laser treatment in diabetic macular edema. Ophthalmology. 2010;117:538-544.

23. Kernt M, Cheuteu R, Vounotrypidis E, et al. Focal and panretinal photocoagulation with a navigated laser (Navilas). Acta Ophthalmol. 2011;89:e662-e664.

24. Kozak I, Kim JS, Oster SF, Chhablani J, Freeman WR. Focal navigated laser photocoagulation in retinovascular disease: clinical results in initial case series. Retina. 2012;32:930-935.

25. Kozak I, Oster SF, Cortes MA, et al. Clinical evaluation and treatment accuracy in diabetic macular edema using navigated laser photocoagulator Navilas. Ophthalmology. 2011;118:1119-1124.

26. Johnson ML, Bush RL, Collins TC, et al. Propensity score analysis in observational studies: outcomes after abdominal aortic aneurysm repair. Am J Surg. 2006;192:336-343.

27. McCaffrey DF, Ridgeway G, Morral AR. Propensity score estimation with boosted regression for evaluating causal effects in observational studies. Psychol Methods. 2004;9:403-425.

28. Silber JH, Rosenbaum PR, Trudeau ME, et al. Multivariate matching and bias reduction in the surgical outcomes study. Med Care. 2001;39:1048-1064.

29. Landrum MB, Guadagnoli E, Zummo R, Chin D, McNeil BJ. Care following acute myocardial infarction in the Veterans Administration Medical Centers: a comparison with Medicare. Health Serv Res. 2004;39:1773-1792.

30. Photocoagulation for diabetic macular edema. Early Treatment Diabetic Retinopathy Study Report no 1. Early Treatment Diabetic Retinopathy Study Research Group. Arch Ophthalmol. 1985;103(12): 1796-1806. 
31. Photocoagulation for diabetic macular edema: Early Treatment Diabetic Retinopathy Study Report no 4. The Early Treatment Diabetic Retinopathy Study Research Group. Int Ophthalmol Clin. 1987;27:265-272.

32. Elman MJ, Aiello LP, Beck RW, et al. Randomized trial evaluating ranibizumab plus prompt or deferred laser or triamcinolone plus prompt laser for diabetic macular edema. Ophthalmology. 2010;117: 1064-1077.
33. Fong DS, Strauber SF, Aiello LP, et al. Comparison of the modified Early Treatment Diabetic Retinopathy Study and mild macular grid laser photocoagulation strategies for diabetic macular edema. Arch Ophthalmol. 2007;125:469-480.

\section{Publish your work in this journal}

Clinical Ophthalmology is an international, peer-reviewed journal covering all subspecialties within ophthalmology. Key topics include: Optometry; Visual science; Pharmacology and drug therapy in eye diseases; Basic Sciences; Primary and Secondary eye care; Patient Safety and Quality of Care Improvements. This journal is indexed on

\section{Dovepress}

PubMed Central and CAS, and is the official journal of The Society of Clinical Ophthalmology (SCO). The manuscript management system is completely online and includes a very quick and fair peer-review system, which is all easy to use. Visit http://www.dovepress.com/ testimonials.php to read real quotes from published authors. 